\title{
Antiviral Therapy in Patients with Viral Hepatitis and Hepatocellular Carcinoma: Indications and Prognosis
}

\author{
Christoph Roderburg Frank Tacke Christian Trautwein \\ Department of Medicine III, University Hospital RWTH Aachen, Aachen, Germany
}

\section{Keywords}

Hepatocellular carcinoma - HCC - Viral hepatitis . Hepatitis B virus - HBV . Hepatitis C virus . HCV . Treatment

\section{Summary}

Background: Chronic hepatitis B and C infections represent major risk factors for the development of hepatocellular carcinoma (HCC). Recently, the management of patients with viral hepatitis has dramatically changed. In the present review we discuss the impact of these developments on the prevention of HCC as well as the treatment of patients with HCC. Methods: Studies indexed in Medline between 1990 and 2015 (November) were reviewed. The terms 'hepatocellular carcinoma', 'HCC', 'hepatitis B', 'hepatitis $C^{\prime}$, 'viral hepatitis', and combinations of these terms were used. Results: Patients with chronic hepatitis B or hepatitis $\mathrm{C}$ without HCC should be evaluated for antiviral therapy, since antiviral therapy was suggested to reduce the risk of HCC development. Cirrhotic patients infected with hepatitis B virus (HBV) require antiviral therapy, while cirrhotics infected with hepatitis $\mathrm{C}$ virus ( $\mathrm{HCV}$ ) need to be prioritized for therapy with interferon (IFN)-free regimens. Antiviral therapy should be considered in HBV-infected patients with HCC, especially to prevent tumor recurrence after curative-intended therapy or to prevent hepatic decompensation. $\mathrm{HCV}$-infected patients with HCC should be considered in similar intention for IFN-free antiviral therapy, depending on the tumor stage and life expectancy. Conclusion: Patients with viral hepatitis should be considered for antiviral treatment for the prevention of HCC development as well as during HCC treatment.

(C) 2016 S. Karger GmbH, Freiburg

\section{Introduction}

Hepatocellular carcinoma (HCC) represents the most common primary malignancy of the liver. With over 600,000 cases diagnosed yearly it is the fifth most common cancer worldwide and the second leading cause of cancer-related death. In more than $80 \%$ of the cases HCC develops within chronically inflamed and cirrhotic livers [1]. Major risk factors include infections with the hepatitis B virus (HBV) or hepatitis $\mathrm{C}$ virus (HCV) and alcohol-related cirrhosis. In addition, non-alcoholic steatohepatitis has recently emerged as a relevant disease etiology [2]. Moreover, it became apparent that other factors such as smoking increases, while e.g. coffee intake decreases the risk for developing an HCC [1].

From a global perspective, viral hepatitis is the leading cause for $\mathrm{HCC}$, because it is a major cause for liver cirrhosis as a prerequisite for HCC. The 5-year cumulative risk of developing HCC for patients with cirrhosis ranges between 5 and 30\%, depending on etiology, region, ethnicity, and stage of cirrhosis. Worldwide, HBV accounts for up to $55 \%$ of the cases of HCC and thus represents the most important risk factor for HCC [3, 4]. Prospective cohort studies showed a 5- to 100-fold increase in the risk for developing HCC in chronically HBV-infected patients [1]. Likewise, meta-analyses of case-control and cross-sectional studies indicated that HBV-infected individuals display a 20 -fold higher risk for HCC than noninfected individuals $[1,4-7]$. The incidence rates for HCC in Asian cohorts were 0.2 per 100 person-years in inactive carriers, 0.6 person-years with chronic HBV infection without cirrhosis, and 3.7 person-years in patients with compensated cirrhosis $[4,8]$. In contrast, there are only few data from European cohorts, which suggests that the HCC incidence ranges from 0.02 per 100 personyears in inactive carriers to 2.2 person-years in subjects with cirrhosis [7]. Although HBV-related HCC mostly occur in patients with established liver cirrhosis, HBV-HCC can also arise in the absence of cirrhosis [4, 7]. Several studies have identified demographic and HBV-related characteristics as predictive for HCC development in the setting of chronic hepatitis B [4, 7]; family history

\section{KARGER \\ Fax +497614520714

Univ.-Prof. Dr. med. Christian Trautwein 
of HCC, older age, and male sex were correlated with the development of HCC. Moreover, longer duration of infection, hepatitis B virus e antigen seropositivity, high viral load, and genotype $\mathrm{C}$ were identified as independent risk factors of HCC development. In addition, high hepatitis B viral load was suggested to correlate with the risk of progression to cirrhosis, highlighting the potential benefit of an efficient antiviral therapy in patients with chronic hepatitis B infection [7].

While hepatitis B globally represents the most important risk factor for HCC, in the developed Western world, only $20 \%$ of HCC cases can be attributed to HBV infection, whereas the majority of HCC cases are suggested to be related to chronic hepatitis $\mathrm{C}$ infection [9]. A recent study reported that HCV was detected in up to $65 \%$ of patients with $\mathrm{HCC}$ in Italy and among $80 \%$ of HCC cases in Japan $[4,10,11]$. The rate of HCC among HCV-infected persons was estimated to range around $3 \%$ in 30 years of observation time [9]. Most HCV-related HCC arise in cirrhotic livers. The Hepatitis C Antiviral Long-Term Treatment Against Cirrhosis (HALT-C) trial even demonstrated that $8 \%$ of patients with advanced fibrosis developed HCC [12]. Besides liver fibrosis/cirrhosis, various other factors such as male sex, old(er) age, metabolic diseases, and alcohol abuse have been associated with the development of HCC in patients with chronic HCV. Moreover, HCV genotype $1 \mathrm{~b}$ and coinfections with HIV or HBV were found more frequently in HCC patients. In contrast to HBV, there seems to be only a weak association between viral load and the risk of progression to HCC $[7,9]$.

While in the past decades a dramatic decrease in cancer mortality was observed for distinct malignancies, the mortality from liver cancer in the USA rose by about 50\% between 1990 and 2005 [13]. At present, despite tremendous scientific and clinical efforts to improve the treatment and diagnosis of HCC, the incidence of HCC still nearly equals its mortality rate [13-15]. Only a minority of about $25 \%$ of patients with HCC are suitable for resection or other potentially curative treatments. For these patients, 5-year survival rates of up to $70 \%$ are possible [13-15]. For the majority of palliative patients, however, classical anticancer agents are ineffective and relatively toxic to HCC patients with impaired liver function [13-15].

With respect to management, current HCC guidelines recommend a stage-dependent treatment approach: Patients at a very early (BCLC 0) or early (BCLC A) stage are candidates for curative treatment approaches such as liver transplantation, resection, and ablation. In case of an intermediate disease stage (BCLC B), transarterial chemoembolization (TACE) should be considered. Those patients with advanced diseases (BCLC C) should be evaluated for a systemic antitumor therapy, for which sorafenib has become the drug of choice in recent years [16-18]. Besides sorafenib, several other agents have been tested for their efficacy in HCC treatment. However, none of them have been successful as a first-line or second-line approach. Sunitinib, brivanib, erlotinib, and linifanib were found to be inferior when directly compared to sorafenib [19]. Brivanib and everolimus have failed to improve survival in second-line treatment after sorafenib [19]. In the same setting, ramucirumab, a novel anti-VEGFR2 antibody, demonstrated only efficacy in a subgroup of patients with alpha-fetoprotein levels >
$400 \mathrm{ng} / \mathrm{ml}$ [20]. Thus, despite these major efforts sorafenib still represents the gold standard in the systemic treatment of HCC. Recent developments include the use of nivolumab, a PD-1 antibody, or c-Met inhibition in case of Met-overexpressing tumors [19].

Because HCC arise in most cases as a result of chronic inflammation in cirrhotic livers [1], efficient HCC treatment is frequently hampered by an impaired liver function in the setting of decompensated or progressive cirrhosis $[4,7]$. Thus, treatment of chronic liver inflammation by providing antiviral treatment might represent a primary and secondary prevention measure in this setting [4, 7]. Accordingly, it was demonstrated in large patient cohorts that a successful antiviral treatment against hepatitis B and hepatitis $C$ can successfully prevent the long-term development of HCC as well as improve survival in patients with established HCC [4, 7]. In the following, we will summarize available treatment strategies in patients with viral hepatitis and highlight how they might be implemented in treatment algorithms of HCC.

\section{Current Treatment Options for Hepatitis B and Implications of Antiviral Therapy for HCC Development}

The ultimate therapeutic goal for HBV-infected patients is the prevention of cirrhosis, cirrhosis complications, and HCC [21]. There are two principal conceptual treatment options for hepatitis (table 1): (a) interferon (IFN)-based therapy, leading to immunemediated control of HBV replication, (b) nucleoside or nucleotide analog therapy, resulting in suppression of HBV replication [22]. Current guidelines, e.g. by the European Association for the Study of the Liver (EASL), summarize the recommendations for the management of hepatitis B [21]. In principle, pegylated IFN therapy (48 weeks) may result in sustained (off-)treatment responses and might induce hepatitis B surface antigen loss, but only in a minority of patients [22]. Nucleos(t)ide analogs do not only suppress the virus but improve liver fibrosis in the majority of patients and can reverse liver cirrhosis [23]. Unfortunately, these drugs are unable to permanently cure viral infection [24]. While IFN can be considered in patients with certain positive predictive factors, nucleos $(\mathrm{t})$ ide analogs will be the treatment of choice for most patients with $\mathrm{HBV}$ infection due to their excellent tolerability, excellent efficacy in suppressing HBV replication, and their applicability even in patients with liver cirrhosis (table 1) [24]. Ongoing studies evaluate the combination of IFN and nucleos(t)ide analogs, aiming at permanently eradicating the virus in selected patients [25].

Tenofovir and entecavir are the two most recently approved nucleos(t)ide analogs that both efficiently suppress HBV replication and have a very low risk of developing resistance. Even after 7 years of therapy, no resistance to tenofovir was detected in patients originally included in the phase III clinical trials [26]. Moreover, the long-term safety profile of both drugs appears favorable, although nucleotide analogs may mildly increase the risk of hip fracture due to osteopenia [27]. Both drugs can be safely administered to patients with advanced fibrosis or cirrhosis. The long-term viral 
Table 1. Current treatment concepts for hepatitis B

Fig.1. Current and investigational treatment options for hepatitis C. IFN-based regimen should not be used in patients with liver cirrhosis. $\mathrm{GT}=$ Genotype; RBV = ribavirin.

\begin{tabular}{|c|c|c|}
\hline & Interferon & Nucleos(t)ide analog \\
\hline Drug(s) of choice & $\begin{array}{l}\text { pegylated interferon alfa-2a, } \\
180 \mu \mathrm{g}, \mathrm{sc}, 1 \times / \text { week }\end{array}$ & $\begin{array}{l}\text { tenofovir } 245 \mathrm{mg} \text {, po, QD } \\
\text { or } \\
\text { entecavir } 0.5 \mathrm{mg} \text {, po, QD }\end{array}$ \\
\hline Treatment duration & 48 weeks, response-guided & long-term \\
\hline $\begin{array}{l}\text { Treatment in liver } \\
\text { cirrhosis }\end{array}$ & not recommended ${ }^{\mathrm{a}}$ & safe, even in liver cirrhosis \\
\hline Advantages & $\begin{array}{l}\text { finite treatment duration, } \\
\text { no resistance, higher rates of } \\
\text { seroconversion with } 48 \text { weeks } \\
\text { of therapy }\end{array}$ & $\begin{array}{l}\text { potent antiviral effect, good } \\
\text { tolerance, oral administration, } \\
\text { safe also in advanced liver diseases }\end{array}$ \\
\hline Disadvantages & $\begin{array}{l}\text { moderate antiviral effect, inferior } \\
\text { tolerability, risk of adverse events, } \\
\text { parenteral administration }\end{array}$ & $\begin{array}{l}\text { indefinite duration (?), potential } \\
\text { risk of resistance, concerns about } \\
\text { long-term safety (renal, osteopenia) }\end{array}$ \\
\hline
\end{tabular}

aPegylated interferon is the treatment of choice in patients with delta hepatitis (HBV-HDV co-/superinfection), but is strictly contraindicated in decompensated cirrhosis.

IFN-containing regimens

\begin{tabular}{|c|}
\hline PegIFN $\alpha+$ RBV + sofosbuvir \\
\hline PegIFN $\alpha+$ RBV + simeprevir \\
\hline
\end{tabular}

IFN-free regimens (approved)

Sofosbuvir/Ledipasvir ( \pm RBV)

Ombitasvir/Paritaprevir/Ritonavir + Dasabuvir ( \pm RBV)

Sofosbuvir + Simeprevir ( \pm RBV)

\begin{tabular}{|l|}
\hline Sofosbuvir + Simeprevir ( \pm RBV) \\
\hline Sofosbuvir + Daclatasvir ( \pm RBV) \\
\hline Ombitasvir/Paritaprevi/Ritonavir ( RBV)
\end{tabular}

IFN-free regimens (investigational)

Grazoprevir + Elbasvir ( \pm RBV)

$$
\text { ABT }-493+\mathrm{ABT}-530
$$

suppression of HBV by nucleos(t)ide analogs is associated with improved survival, reduced rate of cirrhosis complications (e.g. related to portal hypertension), and reduced risk of developing HCC $[22,28,29]$. However, it is important to note that neither entecavir nor tenofovir completely abolish the risk for HCC, especially in patients with liver cirrhosis [30].

\section{Current and Near-Future Treatment Options for Hepatitis C}

The goal of antiviral treatment for hepatitis $\mathrm{C}$ is a complete $\mathrm{HCV}$ eradication. This is currently defined in clinical practice as a sustained virological response (SVR) at 12 weeks after therapy, as assessed by a sensitive molecular method (HCV polymerase chain reaction) with a lower limit of detection $<15 \mathrm{IU} / \mathrm{ml}$ [31]. This surrogate end point has been shown to reflect persistent serum viral eradication [22]. In 2014 and 2015, several new direct-acting antiviral agents (DAAs) have been approved for the treatment of hepatitis C, resulting in an impressive list of therapeutic options (fig. 1). Despite some differences, all these DAAs show a high efficacy and excellent tolerability, which allowed to shorten treatment duration with the new therapeutic regimens and permitted to include patients with comorbidities (e.g. psychiatric disorders) and advanced liver disease [31]. Despite the enormous costs of these options, IFN-free regimens are the best choice because of their virological 
Table 2. Selected IFN-free treatment options for hepatitis C in patients with liver cirrhosis $^{\mathrm{a}}$

\begin{tabular}{|c|c|c|c|c|c|}
\hline & \multicolumn{5}{|l|}{ Genotype } \\
\hline & la & $1 b$ & 2 & 3 & 4 \\
\hline $\begin{array}{c}\text { Compensated } \\
\text { cirrhosis } \\
\text { (Child A) }\end{array}$ & $\begin{array}{l}\text { LDV/SOF/RBV } \\
12 \text { wks or } \\
\text { AbbVie 3D/RBV } \\
24 \text { wks }\end{array}$ & $\begin{array}{l}\mathrm{LDV} / \mathrm{SOF} / \mathrm{RBV} \\
12 \text { wks or } \\
\text { AbbVie } 3 \mathrm{D} \\
12 \text { wks }\end{array}$ & $\begin{array}{l}\text { SOF/RBV } \\
12-16 \text { wks }\end{array}$ & $\begin{array}{l}\mathrm{SOF} / \mathrm{DCV} / \mathrm{RBV} \\
12-16 \mathrm{wks}\end{array}$ & $\begin{array}{l}\text { LDV/SOF/RBV } \\
12 \text { wks or } \\
\text { AbbVie } 2 \mathrm{D} / \mathrm{RBV} \\
12 \text { wks }\end{array}$ \\
\hline $\begin{array}{l}\text { Decompensated } \\
\text { cirrhosis } \\
\text { (Child B-C) }\end{array}$ & $\begin{array}{l}\mathrm{LDV} / \mathrm{SOF} / \mathrm{RBV} \\
12 \mathrm{wks} \text { or } \\
\mathrm{LDV} / \mathrm{SOF} \\
24 \mathrm{wks}\end{array}$ & $\begin{array}{l}\mathrm{LDV} / \mathrm{SOF} / \mathrm{RBV} \\
12 \mathrm{wks} \text { or } \\
\mathrm{LDV} / \mathrm{SOF} \\
24 \mathrm{wks}\end{array}$ & $\begin{array}{l}\text { SOF/RBV } \\
16-24 \text { wks }\end{array}$ & $\begin{array}{l}\mathrm{SOF} / \mathrm{DCV} / \mathrm{RBV} \\
16-24 \mathrm{wks}\end{array}$ & $\begin{array}{l}\text { LDV/SOF/RBV } \\
12 \text { wks or } \\
\text { LDV/SOF } \\
24 \text { wks }\end{array}$ \\
\hline
\end{tabular}

aThe listed regimens represent selected options based on national (DGVS) and international (EASL) recommendations as well as on personal judgment. Treatment choice must also consider prior treatments, comorbidities (renal failure, HIV coinfection), and potential drug-drug interactions.

AbbVie 2D = paritaprevir/ritonavir, ombitasvir; AbbVie 3D = paritaprevir/ritonavir, ombitasvir, and dasabuvir; $\mathrm{DCV}=$ daclatasvir; $\mathrm{LDV}=$ ledipasvir; $\mathrm{SOF}=$ sofosbuvir; $\mathrm{RBV}=$ ribavirin; wks $=$ weeks. efficacy, ease of use, and tolerability [31]. It is expected that at least two additional antiviral drug combinations will be available in 2016: (a) the second-generation protease inhibitor grazoprevir in combination with the NS5A inhibitor elbasvir (developed by Merck) [32, 33], which can be safely used even in patients with renal failure [34], (b) the pan-genotypic NS5A inhibitor velpatasvir in combination with the pan-genotypic polymerase inhibitor sofosbuvir (developed by Gilead Sciences) [35, 36], which can be safely used even in patients with decompensated liver cirrhosis (fig. 1) [37].

In principle, chronic $\mathrm{HCV}$ infection is an indication for antiviral therapy [38], and especially patients with advanced fibrosis, cirrhosis, or decompensated cirrhosis should be prioritized for immediate treatment [31]. There is compelling evidence from several clinical studies that an SVR can provide protection from the development of liver-related complications, hence improving survival of HCV cirrhotics $[22,39,40]$. In addition, the majority of cirrhotic patients subjected to IFN-free therapy improve their liver function as assessed by the MELD (model of end-stage liver disease) score [41]. However, the treatment of HCV-infected patients with liver cirrhosis is challenging and needs to consider the stage of cirrhosis (compensated vs. decompensated), HCV genotype, comorbidities (e.g. renal failure or HIV coinfection), potential drug-drug interactions, and prior treatment experiences (e.g. relapse from DAA therapy) [31]. While sofosbuvir, daclatasvir, or ledipasvir can also be used in decompensated cirrhosis, protease inhibitor-based regimens (e.g. including paritaprevir or simeprevir) should not be used in Child B or $\mathrm{C}$ cirrhotics (table 2). Some uncertainties still exist about the need of ribavirin and the optimal treatment duration with distinct regimens in cirrhotic patients (table 2), and large real-life cohort studies are conducted to verify if the expected SVR rates can be extrapolated from clinical trials into clinical practice. $\mathrm{HCV}$-infected patients with high MELD scores, e.g. exceeding 15 or 20, should primarily be evaluated for liver transplantation, while the benefit of antiviral therapy in this setting is not well established [31].

\section{Antiviral Therapy for the Prevention of HCC}

The gold standard to prevent HBV-related HCC is by means of immunizing infants, i.e. so-called 'primary prevention'. Meanwhile, many different countries have implemented hepatitis B vaccination programs and demonstrated its success. As an example, 20 years after starting the program in Taiwan the incidence of HCC among vaccinated children has dropped by $70 \%$ [9]. Unfortunately, no vaccination is available for $\mathrm{HCV}$ at present [9].

In patients chronically infected with $\mathrm{HBV}$ or $\mathrm{HCV}$, antiviral therapies are the means to avoid or reduce HCC occurrence. Current guidelines define the goal of therapy for chronic hepatitis B as 'to improve quality of life and survival by preventing progression of the disease to cirrhosis, decompensated cirrhosis, end-stage liver disease, HCC and death'. Observational studies showed that IFN therapy reduced $\mathrm{HBV}$ progression to cirrhosis and decreased HCC incidences in Caucasian and Asian patients [42]. Similarly, nucleos $(\mathrm{t})$ ide analogs suppress viral replication, leading to significantly lower HCC incidence rates in Asian patients compared to historical untreated controls [42]. However, for Caucasian patients no data sets are currently available [42]. In this context, the benefit of virological remission was controversial. A large European study (VIRGIL) found after a follow-up of 1.7 years that patients achieving a virological response to entecavir had a $71 \%$ lower probability of a clinical event (HCC, hepatic decompensation, or death) than those who did not [43]. Due to the higher risk of HCC in cirrhotic liver, the beneficial effect of preventing HCC is more apparent in cirrhotic compared to non-cirrhotic HBV-infected patients [43, 44]. Importantly, chronic HBV infection cannot be completely eradicated due to the persistence of covalently closed circular DNA in the nucleus of infected hepatocytes. Moreover, the HBV genome can integrate into the host genome and might favor oncogenesis and the development of HCC [45, 46], highlighting the need for intensive surveillance even in patients with effective viral suppression. 
In $\mathrm{HCV}$-infected patients, several meta-analyses have examined the relationship between SVR and the risk of HCC development, showing a significant HCC reduction in patients with SVR [4, 7]. However, most of these studies are observational as well as retrospective and were based on SVR achieved with IFN-based therapies. Nevertheless, it can be extrapolated that the new IFN-free regimens will also reduce the risk of HCC development. Patients with cirrhosis remain at risk of life-threatening complications; however, hepatic fibrosis may regress upon SVR, thereby reducing the threat of complications such as hepatic failure and portal hypertension. Therefore, current guidelines recommend considering $\mathrm{HCV}$ therapy in all patients with compensated or decompensated chronic liver disease. Importantly, in patients with advanced fibrosis and cirrhosis, $\mathrm{HCV}$ eradication reduces the rate of decompensation and the risk of HCC, which also stresses that HCC surveillance should be continued.

Taken together, all patients with chronic hepatitis B and C should be evaluated for potential treatment as defined in the current guidelines [47]. Successfully treated patients display a lower risk of progressing to liver cirrhosis and HCC.

\section{Antiviral Therapy in Patients with HCC}

Two principal goals of antiviral treatment exist for patients with viral hepatitis: (i) the prevention of tumor recurrence in case of curative-intended treatment, and (ii) the reduction of inflammation and the stabilization of liver function in patients receiving palliative-intended treatments.

Patients receiving curative tumor resection or ablation suffer from recurrence rates of up to $70 \%$ after 5 years, reflecting either intrahepatic metastases (true recurrences) or the development of de novo tumors [48]. Different strategies to prevent recurrence have been tested to prolong tumor-free or overall survival in patients after HCC resection. However, all of these tumor-centered approaches failed in the setting of larger randomized studies, the largest one being the STORM trial [47]. In the last years, nucleos(t)ide analogs have been shown to reduce recurrence and prolong survival after resection of HBV-related HCC and are therefore recommended after curative hepatectomy. Moreover, such a treatment will reduce the risk of hepatic decompensation and progression of liver cirrhosis also in HCC patients at a more advanced stage and should therefore be administered to these patients [4, 7].

Chronic HCV infection represents the leading cause of HCC development in the USA and Europe. IFN-based therapies have been shown to improve outcomes following HCC ablation or resection. However, most of these studies were observational as well as retrospective and were based on older IFN-based treatment pro- tocols. Nevertheless, it appears plausible and highly likely that the high rates of SVR achieved with new IFN-free regimens could also reduce the risk of HCC recurrence following resection or ablation in HCV-infected patients [7]. Due to the underlying chronic liver disease, these patients have an indication for antiviral therapy. This also accounts for patients with more advanced HCC when their life expectancy is higher than 6 months, as eradication of HCV might stabilize liver function and avoid decompensations. Preliminary studies with Child B or C cirrhotic patients, treated for $\mathrm{HCV}$ with sofosbuvir and either ledipasvir or daclatasvir within clinical trials (SOLAR-1/-2 or ALLY-1 trial) or compassionate use programs, indicate that the majority of patients will stabilize or improve their liver function during therapy $[41,49]$.

In summary, patients with $\mathrm{HCC}$ and chronic $\mathrm{HBV}$ or $\mathrm{HCV}$ infection are candidates for antiviral therapy. Treatment might reduce the risk of tumor recurrence or avoid the progression of liver fibrosis, thus increasing the therapeutic window for tumor-specific therapies in these patients.

\section{Recommendations for Antiviral Therapy in Patients with Viral Hepatitis and HCC}

- Patients with chronic hepatitis B or hepatitis C without HCC must be evaluated for antiviral therapy because effective antiviral therapy can reduce the risk of HCC development.

- Patients without HCC but with advanced fibrosis or cirrhosis due to viral hepatitis are at a particularly high risk for HCC development, making HCC surveillance (ultrasound every 6 months) mandatory. $\mathrm{HBV}$-infected cirrhotics require antiviral therapy (entecavir or tenofovir), while HCV-infected cirrhotics need to be prioritized for therapy with IFN-free regimens.

- Antiviral therapy should be considered in HBV-infected patients with HCC, especially to prevent tumor recurrence after curative-intended therapy (e.g. resection) and to prevent hepatic decompensation in cases of advanced liver disease.

- Depending on tumor stage and life expectancy, HCV-infected patients with HCC should be considered for IFN-free antiviral therapy, especially in order to prevent tumor recurrence after curative-intended therapy (e.g., resection) and to prevent hepatic decompensation in cases of advanced liver disease.

- The potential benefit of antiviral therapy in patients with HCC is currently being evaluated in large registry observational studies.

\section{Disclosure Statement}

The authors have nothing to disclose related to this manuscript. 


\section{References}

1 Forner A, Llovet JM, Bruix J: Hepatocellular carcinoma. Lancet 2012;379:1245-1255.

2 Dyson J, Jaques B, Chattopadyhay D, et al: Hepatocellular cancer: the impact of obesity, type 2 diabetes and a multidisciplinary team. J Hepatol 2014;60:110-117.

3 Parkin DM: The global health burden of infection-associated cancers in the year 2002. Int J Cancer 2006; 118:3030-3044.

4 Mittal S, El-Serag HB: Epidemiology of hepatocellular carcinoma: consider the population. J Clin Gastroenterol 2015;47(suppl):S2-6.

5 Shi J, Zhu L, Liu S, Xie WF: A meta-analysis of casecontrol studies on the combined effect of hepatitis $\mathrm{B}$ and $\mathrm{C}$ virus infections in causing hepatocellular carcinoma in China. Br J Cancer 2005;92:607-612.

6 Donato F, Boffetta P, Puoti M: A meta-analysis of epidemiological studies on the combined effect of hepatitis $\mathrm{B}$ and $\mathrm{C}$ virus infections in causing hepatocellular carcinoma. Int J Cancer 1998;75:347-354.

7 El-Serag HB: Epidemiology of viral hepatitis and hepatocellular carcinoma. Gastroenterology 2012;142:12641273.e1261.

8 Fattovich G, Bortolotti F, Donato F: Natural history of chronic hepatitis B: special emphasis on disease progression and prognostic factors. J Hepatol 2008;48: 335-352.

9 Wang CH, Wey KC, Mo LR, Chang KK, Lin RC, Kuo JJ: Current trends and recent advances in diagnosis, therapy, and prevention of hepatocellular carcinoma. Asian Pac J Cancer Prev 2015; 16:3595-3604.

10 Yoshizawa H: Hepatocellular carcinoma associated with hepatitis $\mathrm{C}$ virus infection in Japan: projection to other countries in the foreseeable future. Oncology 2002;62(suppl 1):8-17.

11 Stroffolini T, Andreone P, Andriulli A, et al: Gross pathologic types of hepatocellular carcinoma in Italy. Oncology 1999;56:189-192.

12 Lok AS, Everhart JE, Wright EC, et al: Maintenance peginterferon therapy and other factors associated with hepatocellular carcinoma in patients with advanced hepatitis C. Gastroenterology 2011;140:840849; quiz e812.

13 Roderburg C, Gautheron J, Luedde T: TNF-dependent signaling pathways in liver cancer: promising targets for therapeutic strategies? Dig Dis 2012;30:500-507.

14 Reig M, Darnell A, Forner A, Rimola J, Ayuso C, Bruix J: Systemic therapy for hepatocellular carcinoma: the issue of treatment stage migration and registration of progression using the BCLC-refined RECIST. Semin Liver Dis 2014;34:444-455.

15 Reig M, Gazzola A, Di Donato R, Bruix J: Systemic treatment. Best Pract Res Clin Gastroenterol 2014;28: 921-935.

16 European Association for the Study of the Liver: EASL recommendations on treatment of hepatitis C 2014. J Hepatol;61:373-395.

17 European Association for the Study of the Liver; European Organisation for Research and Treatment of Cancer: EASL-EORTC clinical practice guidelines: management of hepatocellular carcinoma. J Hepatol 2012;56:908-943.

18 Plentz RR, Malek NP: New insights from the German guideline 'hepatocellular carcinoma' (article in German). Dtsch Med Wochenschr 2014;139:2529-2531.
9 Stotz M, Gerger A, Haybaeck J, Kiesslich T, Bullock MD, Pichler M: Molecular targeted therapies in hepatocellular carcinoma: past, present and future. Anticancer Res 2015;35:5737-5744.

20 Zhu AX, Park JO, Ryoo BY, et al: Ramucirumab versus placebo as second-line treatment in patients with advanced hepatocellular carcinoma following first-line therapy with sorafenib (REACH): a randomised, double-blind, multicentre, phase 3 trial. Lancet Oncol 2015; 16:859-870.

21 European Association for the Study of the Liver: EASL clinical practice guidelines: Management of chronic hepatitis B virus infection. J Hepatol 2012;57:167-185.

22 Aghemo A, Lampertico P, Colombo M: Assessing long-term treatment efficacy in chronic hepatitis B and C: between evidence and common sense. J Hepatol 2012;57:1326-1335.

23 Marcellin P, Gane E, Buti M, et al: Regression of cirrhosis during treatment with tenofovir disoproxil fumarate for chronic hepatitis B: a 5-year open-label follow-up study. Lancet 2013;381:468-475.

24 Lampertico P, Maini M, Papatheodoridis G: Optimal management of hepatitis B virus infection - EASL Special Conference. J Hepatol 2015;63:1238-1253.

25 Marcellin P, Ahn SH, Ma X, et al: Combination of tenofovir disoproxil fumarate and peginterferon alfa-2a increases loss of hepatitis B surface antigen in patients with chronic hepatitis B. Gastroenterology 2016;150: 134-144.e10.

26 Buti M, Tsai N, Petersen J, et al: Seven-year efficacy and safety of treatment with tenofovir disoproxil fumarate for chronic hepatitis B virus infection. Dig Dis Sci 2015;60:1457-1464.

27 Wong GL, Tse YK, Wong VW, Yip TC, Tsoi KK, Chan HL: Long-term safety of oral nucleos(t)ide analogs for patients with chronic hepatitis B: a cohort study of 53,500 subjects. Hepatology 2015;62:684-693.

28 Lampertico P, Invernizzi F, Vigano M, et al: The longterm benefits of nucleos(t)ide analogs in compensated HBV cirrhotic patients with no or small esophageal varices: a 12-year prospective cohort study. J Hepatol 2015;63:1118-1125.

29 Papatheodoridis GV, Chan HL, Hansen BE, Janssen HL, Lampertico P: Risk of hepatocellular carcinoma in chronic hepatitis B: assessment and modification with current antiviral therapy. J Hepatol 2015;62:956-967.

30 Papatheodoridis GV, Dalekos GN, Yurdaydin C, et al: Incidence and predictors of hepatocellular carcinoma in Caucasian chronic hepatitis B patients receiving entecavir or tenofovir. J Hepatol 2015;62:363-370.

31 European Association for the Study of the Liver: EASL recommendations on treatment of hepatitis C 2015. J Hepatol 2015;63:199-236.

32 Lawitz E, Gane E, Pearlman B, et al: Efficacy and safety of 12 weeks versus 18 weeks of treatment with grazoprevir (MK-5172) and elbasvir (MK-8742) with or without ribavirin for hepatitis $\mathrm{C}$ virus genotype 1 infection in previously untreated patients with cirrhosis and patients with previous null response with or without cirrhosis (C-WORTHY): a randomised, open-label phase 2 trial. Lancet 2015;385:1075-1086.

33 Zeuzem S, Ghalib R, Reddy KR, et al: Grazoprevir-elbasvir combination therapy for treatment-naive cirrhotic and noncirrhotic patients with chronic hepatitis $\mathrm{C}$ virus genotype 1, 4, or 6 infection: a randomized trial. Ann Intern Med 2015;163:1-13.
4 Roth D, Nelson DR, Bruchfeld A, et al: Grazoprevir plus elbasvir in treatment-naive and treatment-experienced patients with hepatitis $\mathrm{C}$ virus genotype 1 infection and stage 4-5 chronic kidney disease (the CSURFER study): a combination phase 3 study. Lancet 2015;386:1537-1545.

35 Feld JJ, Jacobson IM, Hezode C, et al: Sofosbuvir and velpatasvir for HCV genotype 1, 2, 4, 5, and 6 infection. N Engl J Med 2015;373:2599-2607.

36 Foster GR, Afdhal N, Roberts SK, et al: Sofosbuvir and velpatasvir for HCV genotype 2 and 3 infection. N Engl J Med 2015;373:2608-2617.

37 Curry MP, O’Leary JG, Bzowej N, et al: Sofosbuvir and velpatasvir for HCV in patients with decompensated cirrhosis. N Engl J Med 2015;373:2618-2628.

38 Sarrazin C, Berg T, Buggisch P, et al: S3 guideline hepatitis $\mathrm{C}$ addendum (article in German). Z Gastroenterol 2015;53:320-334.

39 van der Meer AJ, Veldt BJ, Feld JJ, et al: Association between sustained virological response and all-cause mortality among patients with chronic hepatitis $\mathrm{C}$ and advanced hepatic fibrosis. JAMA 2012;308:2584-2593.

40 van der Meer AJ, Wedemeyer H, Feld JJ, Dufour JF, Zeuzem S, Hansen BE, Janssen HL: Life expectancy in patients with chronic $\mathrm{HCV}$ infection and cirrhosis compared with a general population. JAMA 2014;312: 1927-1928.

41 Charlton M, Everson GT, Flamm SL, et al: Ledipasvir and sofosbuvir plus ribavirin for treatment of $\mathrm{HCV}$ infection in patients with advanced liver disease. Gastroenterology 2015;149:649-659.

42 Papatheodoridis GV, Manolakopoulos S, Touloumi G et al: Hepatocellular carcinoma risk in HBeAg-negative chronic hepatitis B patients with or without cirrhosis treated with entecavir: HepNet.Greece cohort. J Viral Hepat 2015;22:120-127.

43 Zoutendijk R, Reijnders JG, Brown A, et al: Entecavir treatment for chronic hepatitis B: adaptation is not needed for the majority of naive patients with a partial virological response. Hepatology 2011;54:443-451.

44 Hosaka T, Suzuki F, Kobayashi M, et al: Long-term entecavir treatment reduces hepatocellular carcinoma incidence in patients with hepatitis B virus infection. Hepatology 2013;58:98-107.

45 Nassal M: HBV cccDNA: viral persistence reservoir and key obstacle for a cure of chronic hepatitis B. Gut 2015;64:1972-1984.

46 Noordeen F: Hepatitis B virus infection: an insight into infection outcomes and recent treatment options. Virusdisease 2015;26:1-8.

47 Bruix J, Takayama T, Mazzaferro V, et al: Adjuvant sorafenib for hepatocellular carcinoma after resection or ablation (STORM): a phase 3, randomised, doubleblind, placebo-controlled trial. Lancet Oncol 2015;16: 1344-1354.

48 Tabor E: Hepatocellular carcinoma: global epidemiology. Dig Liver Dis 2001;33:115-117.

49 Pawlotsky JM, Feld JJ, Zeuzem S, Hoofnagle JH: From non-A, non-B hepatitis to hepatitis $\mathrm{C}$ virus cure. J Hepatol 2015;62:S87-99. 